Hydrol. Earth Syst. Sci., 15, 3861-3875, 2011

www.hydrol-earth-syst-sci.net/15/3861/2011/

doi:10.5194/hess-15-3861-2011

(C) Author(s) 2011. CC Attribution 3.0 License.

\title{
What can we learn from long-term groundwater data to improve climate change impact studies?
}

\author{
S. Stoll ${ }^{1}$, H. J. Hendricks Franssen ${ }^{2}$, R. Barthel ${ }^{3}$, and W. Kinzelbach ${ }^{1}$ \\ ${ }^{1}$ Institute of Environmental Engineering, ETH Zurich, 8093 Zurich, Switzerland \\ ${ }^{2}$ Agrosphere, IBG-3, Forschungszentrum Jülich GmbH, 52425 Jülich, Germany \\ ${ }^{3}$ Institute of Hydraulic Engineering, Universität Stuttgart, 70569 Stuttgart, Germany
}

Received: 3 August 2011 - Published in Hydrol. Earth Syst. Sci. Discuss.: 8 August 2011

Revised: 9 November 2011 - Accepted: 12 December 2011 - Published: 21 December 2011

\begin{abstract}
Future risks for groundwater resources, due to global change are usually analyzed by driving hydrological models with the outputs of climate models. However, this model chain is subject to considerable uncertainties. Given the high uncertainties it is essential to identify the processes governing the groundwater dynamics, as these processes are likely to affect groundwater resources in the future, too. Information about the dominant mechanisms can be achieved by the analysis of long-term data, which are assumed to provide insight in the reaction of groundwater resources to changing conditions (weather, land use, water demand). Referring to this, a dataset of 30 long-term time series of precipitation dominated groundwater systems in northern Switzerland and southern Germany is collected. In order to receive additional information the analysis of the data is carried out together with hydrological model simulations. High spatio-temporal correlations, even over large distances could be detected and are assumed to be related to large-scale atmospheric circulation patterns. As a result it is suggested to prefer innovative weather-type-based downscaling methods to other stochastic downscaling approaches. In addition, with the help of a qualitative procedure to distinguish between meteorological and anthropogenic causes it was possible to identify processes which dominated the groundwater dynamics in the past. It could be shown that besides the meteorological conditions, land use changes, pumping activity and feedback mechanisms governed the groundwater dynamics. Based on these findings, recommendations to improve climate change impact studies are suggested.
\end{abstract}

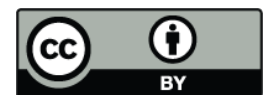

Correspondence to: S. Stoll (stoll@ifu.baug.ethz.ch)

\section{Introduction}

Groundwater is one of the major water resources used to meet public water demand. For example in Switzerland more than $80 \%$ of the drinking water is derived from groundwater. Moreover groundwater is essential for ecosystems like wetlands and delivers most of the stream water during droughts. Facing global environmental change including climate change, land use change and eventually adaptation processes, it is essential to assess the impact of all those on groundwater recharge and resources. Changes in the distribution and the amount of precipitation, increasing temperatures, increasing demand (through population growth and increased irrigation requirements) and continued sealing of surfaces can easily increase the pressure on groundwater.

Although the focus of climate change impact studies in the past has been mainly on surface water, more attention has been paid to groundwater related questions recently (Green et al., 2011). Climate change impact studies are usually conducted in a standard manner: typically, a climate model is used to estimate the changes of the atmospheric conditions, driven by different emission scenarios in the future. As climate model outputs are too coarse for direct application to regions, downscaling methods are applied to bridge the gap. The downscaled climate projections are then used to drive suitable hydrological models. The uncertainty of the climate impact studies can be attributed in the first place to the climate models and the emission scenarios. Recent studies (Chen et al., 2011; Stoll et al., 2011; Crosbie et al., 2011) showed that apart from the uncertainty of the climate models also the downscaling process contributes significantly to the uncertainty of the results of impact studies. The fraction of uncertainty related to the hydrological part

Published by Copernicus Publications on behalf of the European Geosciences Union. 
of the modeling chain is comparatively smaller (Crosbie et al., 2011; Kingston and Taylor, 2010; Gosling et al., 2011). However, according to Bastola et al. (2011) “(...) hydrological model uncertainty has a significant role in the uncertainty envelopes of future climate change impacts and should be routinely considered in assessments (...)". Consequently, at the end of the typical model chain approach used in climate change impact studies, multiple significant sources of uncertainty affect the results, making it very difficult to get reliable projections of future hydrological fluxes (Stoll et al., 2011; Crosbie et al., 2011; Beven, 2011). The question arises whether (given the uncertainties) climate change impact studies are meaningful or whether they are "(...) just like throwing a dice" (Blöschl and Montanari, 2010). Blöschl and Montanari (2010) argue that besides the magnitude and direction of the changes it is most important to understand and explain why certain changes are projected. Therefore, to improve climate change studies, dealing with the impact on groundwater resources, it would be of the utmost importance to identify dominant processes affecting groundwater dynamics.

The analysis of long-term (50 yr) and large-scale groundwater data sets (i.e. considering many observation wells from a large region) can help to gain additional insights into the relevant processes. Time series of groundwater levels and spring flows are assumed to contain valuable proxy information on past changes in recharge and their interaction with anthropogenic activity, land use and meteorological conditions. Analyzing those data can help to identify processes which will affect groundwater resources in the future and are worth to be considered in impact studies. For example, studies (Warren, 1994; Bradford, 2000) point to the fact that especially low winter precipitation is associated with (posterior) low groundwater levels. Thus changes in the temporal distribution of the precipitation could have a large impact, and are important to consider when doing impact studies. Additionally, the analysis of aquifers, exploited to meet the water demand can help to classify the importance of water abstractions (Wada et al., 2010), and compare them with the groundwater drawdowns introduced by meteorological causes.

So far, analyses of long-term and large-scale data sets with respect to the interaction with climate variability are quite rare. Rivard et al. (2009) performed trend analyses for several long-term groundwater level time series across Canada and found an almost equal number of decreasing and increasing trends. Hanson et al. (2006) examined the relationship between groundwater levels and climate variability across the southwestern United States and detected significant correlation between groundwater dynamics and large-scale climatic cycles like the Pacific Decadal Oscillation (PDO). The number of studies is larger if we also consider analyses for smaller regions and shorter time series. For example Barco et al. (2010) found not only correlations between groundwater levels in Californian aquifers and the PDO, but strong relationships to the El Nino-Southern Oscillation. Chen et al.
(2004) focused on the connection between climate variability and groundwater levels around Winnipeg, Canada for a period of $35 \mathrm{yr}$ and found strong correlations between precipitation and groundwater dynamics. Similar results were found for a European study. Over a period of more than 70 yr Fiorillo and Guadagno (2010) found a strong relationship between a precipitation based drought index and the discharge of a karstic spring in southern Italy near Naples. Also for Europe, teleconnection patterns and corresponding hydrogeological responses have been analyzed. Holman et al. (2009) detected a relationship between the North Atlantic Oscillation and the dynamics of a chalk aquifer in the UK. Apart from the direct analysis of the relationship between groundwater dynamics and climate variability, longterm groundwater data are used to calibrate the parameters of auto-regressive models which are afterwards applied to climate change scenarios (e.g. Okkonen and Klove, 2010).

We collected a dataset of groundwater level and spring outflow data in northern Switzerland and southern Germany, representing conditions in aquifers which are dominated by direct recharge, ensuring a direct connection between the atmosphere and the groundwater. In this study, it is analyzed to what extent this dataset can deliver information about processes controlling the groundwater behavior in the past. If it is possible to identify these processes, conclusions about risks for groundwater resources can be drawn. Trend tests and spatio-temporal analyses are performed to detect significant changes and patterns in the groundwater dynamics. With the help of recharge calculations it is then tried to relate the observed patterns (e.g. droughts) with possible causes (e.g. precipitation deficits). By analyzing a large dataset with several groundwater bodies, a distinction between local and large-scale phenomena can be obtained. To distinguish between the climatic and direct anthropogenic causes a qualitative procedure is established, based on different sources of information. Among the possible dominating processes, a focus on the intra-annual distribution of precipitation, land use changes and the role of a variable water demand is laid. Based on these analyses we will try to give recommendations to improve climate change impact studies on groundwater systems.

\section{Data and methods}

\subsection{Data set}

For this study groundwater data in Switzerland were collected and supplemented by data from southern Germany. In order to detect a relation with climatic variations, the following selection criteria are applied. (1) Only unconfined aquifers which are dominated by direct recharge are considered. (2) The time series cover a time span of at least $30 \mathrm{yr}$ with a monthly resolution. (3) Time series showing obvious anthropogenic alterations like sudden discontinuities are 

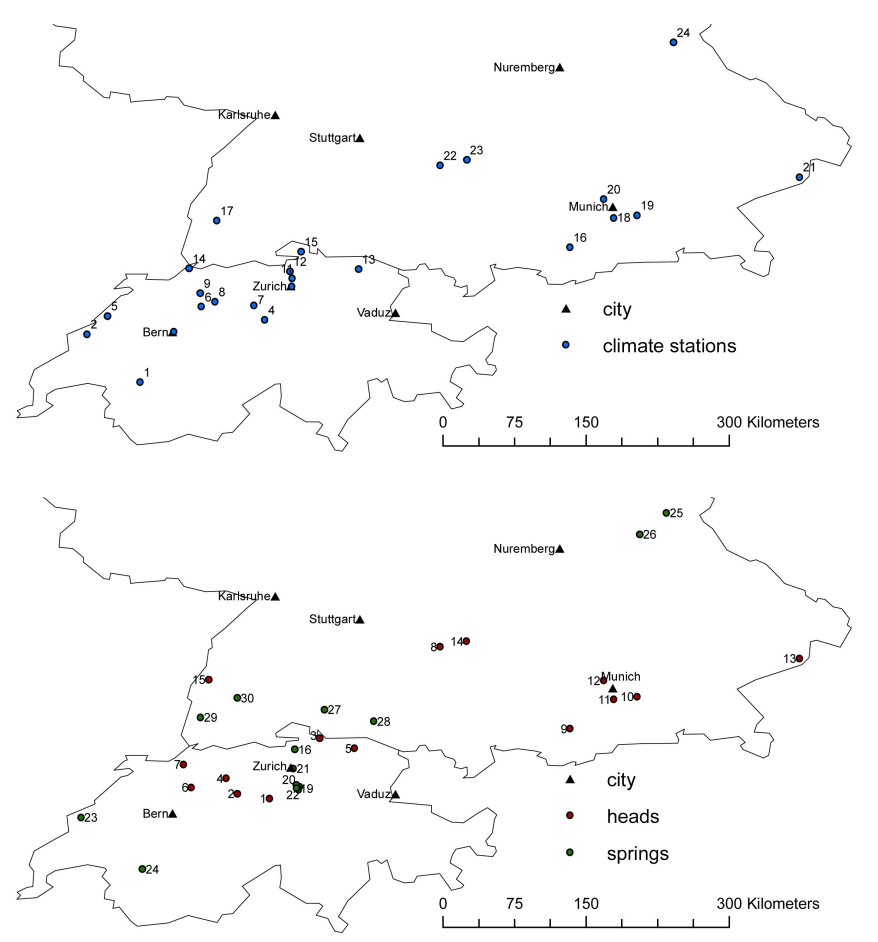

Fig. 1. Locations of the selected climatological stations (top) and groundwater monitoring sites (bottom) in northern Switzerland and southern Germany.

excluded. In the end 16 Swiss and 14 German series out of several hundred were selected (Fig. 1). The Swiss data are made available by the working group Climate and Groundwater of the Swiss Hydrogeological Society. The German data are provided by Baden-Württemberg and Bavaria State Environmental Agencies. In Table 1 all selected time series and additional information about climatic and geological properties are presented. The specified land use is the type of land use prevailing close to the monitoring site. Land use in the unknown corresponding catchment can differ. The time series represent a wide range of aquifer types in a moderate humid climate. The meteorological forcing for the recharge calculations is derived from nearby climate stations (Fig. 1, Table 2) preferably at similar elevations and whenever possible covering the same period of time. For some of the German locations (8-14) additional regionalized climate data are provided by PROMET (Mauser and Bach, 2009). Besides the meteorological conditions, pumping activity and land use changes are considered to be also important factors which could be responsible for patterns and trends in the time series. Unfortunately, for very long time series, hardly any data about land use changes and, especially, pumping rates are available.

\subsection{Model approach}

To relate observed trends and patterns in the time series with possible causes (like an increase of evapotranspiration) additional information about the recharge conditions is necessary. Recharge and groundwater level dynamics are closely linked. When recharge is increased, increasing groundwater levels are expected. For example, this relationship is exploited to calculated effective recharge on the basis of groundwater table fluctuations (e.g. Zhang et al., 2011). On the other hand, recharge calculations can also deliver information about the causes of the groundwater anomalies. Therefore, we established one dimensional MIKE SHE models (Graham and Butts, 2006) to calculate the groundwater recharge.

In contrast to the observed time series, the model calculations are designed to be independent of anthropogenic actions. Land use changes and pumping are not considered in the model set up. Thus the recharge calculations directly represent the influence of the meteorological conditions (precipitation and evapotranspiration) on the groundwater dynamics and do not contain the signature of secondary processes (landuse change and pumping). The model results are compared with the groundwater observations. Thus, the model is used to identify which of the observed features in the groundwater data (e.g. trends, pronounced droughts) correspond with the climate signal (as produced by the recharge modelling). If it is not possible to relate the observed features with the climate signal, secondary processes are assumed to prevail, which we will try to identify.

The models consider snowmelt and interception processes to calculate the amount and timing of the infiltration. Surface runoff is neglected and accordingly all water infiltrates into the soil. To calculate the snow melt, a degree-day approach is chosen. Potential Evapotranspiration is calculated following the FAO Penman-Monteith approach (Allen et al., 1998) and the method by Kristensen and Jensen (1975) is used to calculate actual evapotranspiration as a function of soil moisture and the leaf area index. The flow in the unsaturated zone is modeled by Richards' equation, parameterized according to the methods of Mualem (1976) and van Genuchten (1980). 1-D calculations cannot account for the variability of soil properties in the catchments. Therefore and as there is generally little information about the actual soil properties and their variability, the soil parameterization is identical for all sites. Loamy sand, as a typical soil in the perialpine region, is chosen as reference. Saturated hydraulic conductivity was set to $10^{-5}\left(\mathrm{~m} \mathrm{~s}^{-1}\right)$, saturated water content to $0.35(-)$, residual water content to 0.03 (-) and the Mualem - Van Genuchten parameters $\alpha$ to $0.03\left(\mathrm{~cm}^{-1}\right)$ and $n$ to 2.2 (-). The average observed groundwater level acts as lower boundary condition. As the average groundwater depth in the catchment is unknown for the spring locations, the depth of the lower boundary is estimated. The models are not subject to calibration. All parameters were estimated a priori according to literature values. No land use changes are 
Table 1. Analyzed groundwater time series (see also Fig. 1 for the exact locations) with elevation (m a.s.1.), average groundwater depth in meter below terrain (Depth/Discharge) or mean annual discharge $\left(1 \mathrm{~s}^{-1}\right)$, mean annual precipitation in mm a ${ }^{-1}$ (1971-1990), mean annual temperature in ${ }^{\circ} \mathrm{C}(1971-1990)$ and the number of the precipitation (\#P) and climate station (\#C), used to calculate the recharge .

\begin{tabular}{|c|c|c|c|c|c|c|c|c|c|c|c|c|}
\hline \# & Location & Lithology & Type & Start & End & $\begin{array}{r}\text { Ele- } \\
\text { vation }\end{array}$ & $\begin{array}{r}\text { Depth }(\mathrm{m}) / \\
\text { Discharge }\left(1 \mathrm{~s}^{-1}\right)\end{array}$ & Land use & $\begin{array}{r}\text { Tempera- } \\
\text { ture }\end{array}$ & $\begin{array}{r}\text { Precipi- } \\
\text { tation }\end{array}$ & $\# \mathrm{P}$ & \#C \\
\hline 1 & Ebikon & quaternary moraine deposit & level & 1 Jan 1976 & 15 Mar 2007 & 420 & 3.3 & urban, agriculture & 9.0 & 1202 & 7 & 4 \\
\hline 2 & Grosswangen & quaternary fluvial gravel & level & 1 Jan 1974 & 31 Dec 2007 & 535 & 5.2 & agriculture & 8.7 & 1109 & 7 & 4 \\
\hline 3 & Etzwilen & quaternary gravel & level & 10 Jan 1933 & 31 Dec 2007 & 440 & 3.9 & agriculture, forest & 8.6 & 909 & 15 & 15 \\
\hline 4 & Zofingen & quaternary fluvial gravel & level & 1 Jan 1975 & 31 Dec 2007 & 433 & 9.0 & urban, agriculture & 8.3 & 1124 & 8 & 3 \\
\hline 5 & Mauren & quaternary moraine deposit & level & 1 Oct 1924 & 1 Mar 2008 & 433 & 9.0 & agriculture & 8.4 & 1014 & 13 & 15 \\
\hline 6 & Subingen & quaternary gravel & level & 1 Jan 1968 & 1 May 2007 & 443 & 12.0 & agriculture, urban & 8.4 & 1100 & 6 & 3 \\
\hline 7 & Breitenbach & quaternary gravel & level & 1 Jan 1969 & 31 Dec 2007 & 390 & 18.0 & agriculture, urban & 8.9 & 980 & 9 & 14 \\
\hline 8 & Westerstetten & karst & level & 1 Feb 1957 & $26 \operatorname{Mar} 2007$ & 537 & 8.9 & agriculture, forest & 7.4 & 803 & 22 & 22 \\
\hline 9 & Tauting & quaternary moraine deposit & level & 10 Jan 1975 & 27 Jun 2007 & 638 & 24.7 & agriculture, forest & 7.7 & 1198 & 16 & 16 \\
\hline 10 & Wolfersberg & quaternary fluvial gravel & level & 7 Jun 1938 & 9 Dec 2002 & 580 & 34.8 & forest & 7.5 & 1088 & 19 & 19 \\
\hline 11 & Oberhaching & quaternary fluvial gravel & level & 7 Jun 1938 & $6 \mathrm{Jul} 2005$ & 572 & 2.4 & urban, agriculture & 7.7 & 1044 & 18 & 18 \\
\hline 12 & Ludwigsfeld & quaternary fluvial gravel & level & 7 Jul 1941 & $11 \mathrm{Jul} 2005$ & 498 & 1.8 & urban, agriculture & 7.9 & 900 & 20 & 20 \\
\hline 13 & Pocking & quaternary fluvial gravel & level & 22 Nov 1937 & 5 Jun 2007 & 317 & 2.8 & urban, agriculture & 8.3 & 838 & 21 & 21 \\
\hline 14 & Niederstotzingen & quaternary fluvial gravel & level & 25 Aug 1960 & 24 Apr 2006 & 455 & 1.1 & forest, agriculture & 7.5 & 739 & 23 & 23 \\
\hline 15 & Herbolzheim & quaternary fluvial gravel & level & 4 Nov 1968 & 27 Dec 2006 & 174 & 2.2 & agriculture, forest & 9.4 & 903 & 17 & 17 \\
\hline 16 & Freienstein & quaternary gravel & spring & 1 Aug 1960 & 31 Aug 2008 & 620 & 1.4 & forest & 7.5 & 1205 & 12 & 11 \\
\hline 17 & Sihlsprung & quaternary moraine deposit & spring & 1 Jan 1903 & 30 Nov 2007 & 600 & 3.7 & agriculture, forest & 7.5 & 1436 & 10 & 10 \\
\hline 18 & Hinterberg & quaternary moraine deposit & spring & 1 Jan 1903 & 30 Nov 2007 & 610 & 3.4 & agriculture, forest & 7.2 & 1436 & 10 & 10 \\
\hline 19 & Wilen & quaternary moraine deposit & spring & 1 Mar 1905 & 30 Nov 2007 & 680 & 1.2 & agriculture, forest & 7.3 & 1515 & 10 & 10 \\
\hline 20 & $\mathrm{Eu}$ & quaternary moraine deposit & spring & 1 Oct 1917 & 30 Nov 2007 & 668 & 2.2 & agriculture, forest & 7.5 & 1491 & 10 & 10 \\
\hline 21 & Dolder & quaternary moraine deposit & spring & 1 Jan 1933 & 30 Nov 2007 & 540 & 17.1 & forest & 8.4 & 1110 & 10 & 10 \\
\hline 22 & Steingass & quaternary moraine deposit & spring & 1 Jan 1903 & 1 Nov 2007 & 585 & 0.3 & agriculture, forest & 7.6 & 1391 & 10 & 10 \\
\hline 23 & St. Sulpice & karst & spring & 1 Jan 1964 & 31 Dec 2007 & 775 & 5002.1 & agriculture, forest & 7.4 & 1513 & 2 & 5 \\
\hline 24 & L'Etivaz & marl shists & spring & 1 Feb 1970 & 11 Jan 2001 & 1160 & 1.0 & forest, agriculture & 4.5 & 1641 & 1 & 1 \\
\hline 25 & Steinreuth & mica shists, gneiss & spring & 7 May 1951 & 26 Mar 2007 & 620 & 2.6 & agriculture, forest & 7.5 & 685 & 24 & 24 \\
\hline 26 & Adlholz & sandstone & spring & 14 May 1951 & 21 May 2007 & 500 & 5.8 & agriculture, forest & 7.5 & 685 & 24 & 24 \\
\hline 27 & Emmingen & karst & spring & 12 Nov 1956 & 19 Feb 2007 & 799 & 2.5 & agriculture, forest & 6.9 & 801 & 13 & 15 \\
\hline 28 & Heiligenberg & quaternary moraine deposit & spring & 1 Nov 1954 & 2 Apr 2007 & 708 & 2.4 & forest, agriculture & 6.7 & 858 & 13 & 15 \\
\hline 29 & Sulzburg & quaternary fluvial gravel & spring & 14 Nov 1955 & 23 Apr 2007 & 306 & 0.6 & forest & 9.7 & 1006 & 17 & 17 \\
\hline 30 & Rötenbach & sandstone & spring & 2 Nov 1953 & 19 Mar 2007 & 835 & 2.0 & forest & 5.7 & 1249 & 17 & 17 \\
\hline
\end{tabular}

implemented in the recharge calculations, meaning that the parameterization of the vegetation stays constant over time. Not for each monitoring site an individual recharge calculation is performed. Due to the geographic proximity of some monitoring sites and a shortage of long-term climate data, data from the same climate station is used to calculate the recharge for different groundwater monitoring sites (see Table 1). Thus to compare with the observed data, an identical model setup is used to calculate the recharge for the sites $1 / 2$, $17 / 18 / 19 / 20 / 21 / 22,25 / 26,5 / 27 / 28$ and 15/29/30.

\subsection{Time series analysis}

Besides the calculation of correlation coefficients, a principal component analysis (PCA) is applied to analyze the spatiotemporal correlations and to extract the essential information from the groundwater data and the model calculations. PCA is a standard method for dealing with large datasets. Typical fields of applications are studies focusing on teleconnections (e.g. Ryu et al., 2010), downscaling (Fowler et al., 2007) or hydrochemistry (e.g. Helena et al., 2000). The method seeks to represent a large fraction of the total variance of a multivariate dataset by a few so-called principal components. It is based on an eigenvalue decomposition of a correlation matrix of the entire dataset. The principle components or in other words the dominant modes of the variability can be visualized by the PCA loadings and scores. Loadings represent the pattern of the modes, while the scores characterize the amplitude of the modes over time. Hence, the score can be interpreted as measure of the groundwater dynamics, representing the whole study area. Accordingly, the score of the observed time series can thus be used to analyze largescale anomalies and their interaction with the climate signal as represented by the score of the recharge calculations.

In addition to the PCA, we apply the widely used rank-based non-parametric Mann-Kendall test (Mann, 1945; Kendall, 1975) to detect trends in the groundwater time series (which can be introduced by different causes). The Nullhypothesis assumes independent, identically distributed time series values whereas the alternative hypothesis assumes that there is a monotonic trend. As the test is based on the relative ranking of the data, it is less sensitive to outliers and does not require normally distributed data. However, von Storch (1995) showed that the test is responsive to serial correlation, which can result in false rejections of the Null-Hypothesis. Therefore, the methodology of the Trend Free Pre-Whitening according to Yue and Wang (2002) is applied: first the slope according to Sen (1968) is detected and removed. Based on the de-trended original time series, the method removes the first order autocorrelation resulting in a new time series. The trend is re-added and the Mann-Kendall trend test is applied again. 


\section{Results}

\subsection{Recharge calculations}

To allow modelling as additional source of information, it is necessary that the calculations generally correspond with the observations. However, deviations between model and observations can also provide information about processes not included in the model. As calculated recharge values cannot be compared directly with measured groundwater levels or spring discharges, and the main interest is the groundwater dynamics, monthly values are normalized (by substracting the average and dividing by the standard deviation) and a twelve month running average is calculated. Table 3 shows correlations between smoothed, observed groundwater data and smoothed recharge calculations. For most of the time series reasonable correlations between the model and the observed data are found, with better results for the springs than for the groundwater level sites. The best performance is reached for the spring in St. Sulpice with a linear correlation coefficient between model and data of 0.91 , whereas no correlation was found for the groundwater level in Etzwilen. Also visually, groundwater level (Fig. 2) and spring discharge (Fig. 3) dynamics correspond well with the results of the uncalibrated model runs. The general behavior is represented, although time shifts (e.g. Wolfersberg) and deviating trends (e.g. Etzwilen) can be recognized. Minima in groundwater level, groundwater recharge and spring discharge are highly correlated with the corresponding precipitation amounts. Additionally, groundwater level data usually show more pronounced minima than the spring discharge data or the calculated recharge (e.g. Ludwigsfeld, Niederstotzingen).

To extract the dominating mode from all time series a principle component analysis is applied to the monthly groundwater data and the calculated deep percolation from the root zone. Deep percolation instead of recharge is chosen to enable a better comparison between sites, strongly reducing the impact of the delayed recharge in case of a deep groundwater table. In order to eliminate gaps in the PCA score related with missing values in the observed time series, not all time series could be incorporated and a reduction is necessary. Additionally, to avoid a weight bias, only one time series each is selected from regions with a high density of monitoring sites. The chosen calculated $(3,5,8,9,10,12$, $13,15,16,18,23,24$ and 25) and observed $(3,8,13,16,18$, $26,27,28$ and 30) times series are assumed to represent the whole study area. The first principal component of the observed data explains $43 \%$ of the variance, while the first principal component of the model calculations explains $63.2 \%$ of the variance. Higher order components contribute only little to the variance and are not considered. The loadings of the first principle component show a uniform pattern indicating synchronous dynamics. Figure 4 shows the monthly principal component score of calculated deep percolation and
Table 2. Name and type ( $\mathrm{P}=$ only precipitation data, $\mathrm{C}=$ precipitation and additional meteorological data) of climatological stations (* regionalized climate data).

\begin{tabular}{lll}
\hline$\#$ & location & type \\
\hline 1 & Chateau-d'Oex & $\mathrm{C}$ \\
2 & Couvet & $\mathrm{P}$ \\
3 & Bern & $\mathrm{C}$ \\
4 & Luzern & $\mathrm{C}$ \\
5 & La Chaux-de-Fonds & $\mathrm{C}$ \\
6 & Herzogenbuchsee & $\mathrm{P}$ \\
7 & Beronmünster & $\mathrm{P}$ \\
8 & St. Urban & $\mathrm{P}$ \\
9 & Balsthal & $\mathrm{P}$ \\
10 & Zürich-Fluntern & $\mathrm{C}$ \\
11 & Kloten & $\mathrm{C}$ \\
12 & Bülach & $\mathrm{P}$ \\
13 & Sulgen & $\mathrm{P}$ \\
14 & Basel & $\mathrm{C}$ \\
15 & Schaffhausen & $\mathrm{C}$ \\
16 & Tauting & $\mathrm{C}^{*}$ \\
17 & Freiburg & $\mathrm{C}$ \\
18 & Oberhaching & $\mathrm{C}^{*}$ \\
19 & Wolfersberg & $\mathrm{C}^{*}$ \\
20 & Ludwigsfeld & $\mathrm{C}^{*}$ \\
21 & Pocking & $\mathrm{C}^{*}$ \\
22 & Westerstetten & $\mathrm{C}^{*}$ \\
23 & Niederstotzingen & $\mathrm{C}^{*}$ \\
24 & Weiden & $\mathrm{C}$ \\
\hline
\end{tabular}

observed groundwater data for the period 1961-2006. The two scores have very similar temporal dynamics, and only a small temporal lag appears between the two signals. The major groundwater drought event occurred in the period between 1971 and 1973. Other important droughts occurred in the periods 1962-1964, 1976/1977, 1983-1985, 1989-1992, 1996-1998 and 2003.

\subsection{Correlations}

Figure 5 shows the spatial correlations among the different sites for groundwater data (on a monthly basis) and, at the same sites, also for the calculated deep percolation from the root zone. In general, the correlations are positive and most of them are significant $(p=0.01)$. Three patches of high correlations can be identified, grouping around the monitoring sites $2-6,8-13$ and $17-22$. Even over very large distances like for example between sites 3 and 14 (approx. $350 \mathrm{~km}$ ) or sites 25 and 29 (approx. $390 \mathrm{~km}$ ) distinct correlations larger than 0.5 are found. On the other hand, monitoring site 27 hardly shows positive correlations with any of the other sites. The correlations among the sites found for the calculated percolation are clearly higher than for the measured data. All calculated correlations are significant $(p=0.01)$ and the average Spearman correlation coefficient is 0.65 . Also the calculated percolation shows high correlations over large distances. The high correlations are also observable for average 

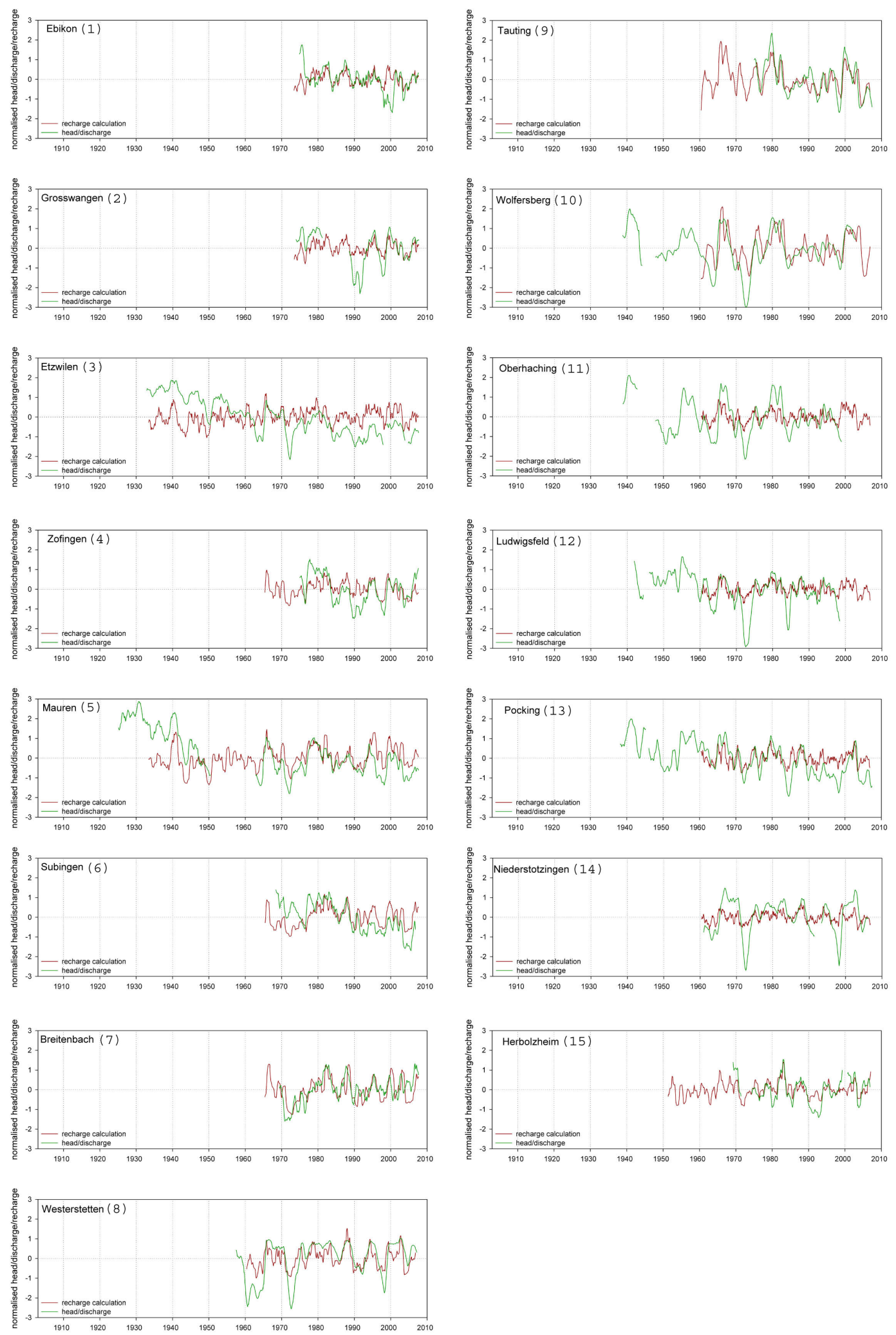

Fig. 2. Normalised monthly observed head data versus calculated recharge for the different groundwater sites over periods of varying length between 1930 and 2010 . 

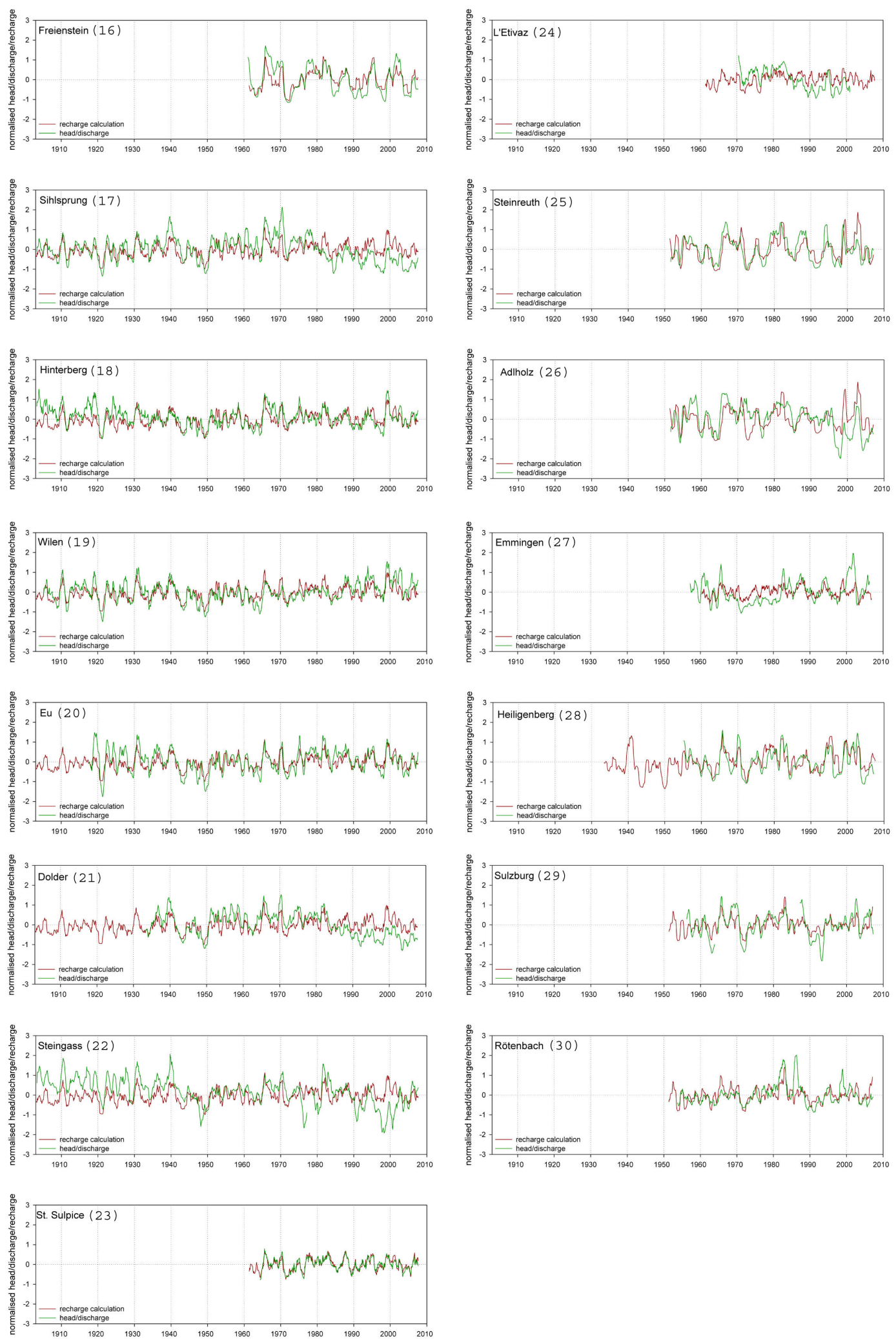

Fig. 3. Normalised monthly observed spring discharges versus calculated recharge for the different springs over periods of varying length between 1930 and 2010. 


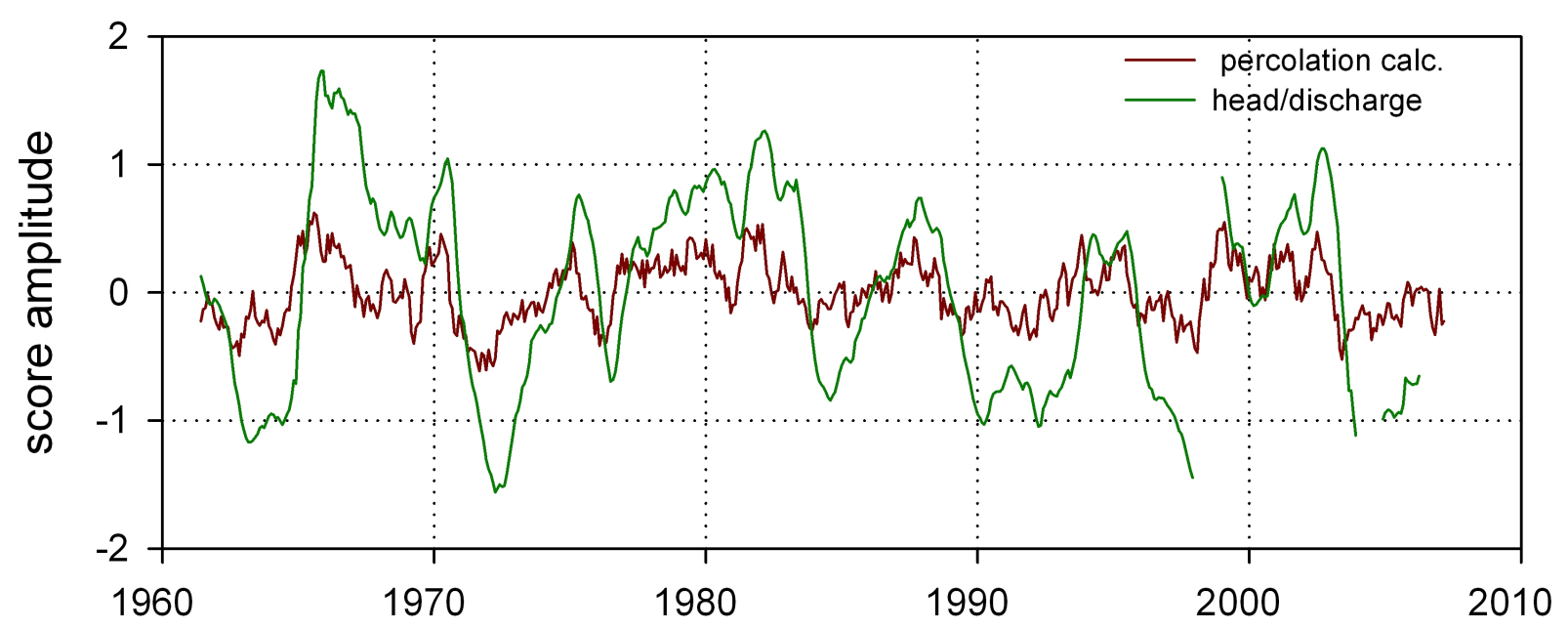

Fig. 4. Monthly principle component scores of percolation calculations and groundwater data for the period 1961-2006.

Table 3. Spearman and Pearson correlations between normalised observed groundwater data and calculated recharge.

\begin{tabular}{rrr}
\hline$\#$ & Spearman & Pearson \\
\hline 1 & 0.34 & 0.31 \\
2 & 0.46 & 0.57 \\
3 & 0.02 & 0.01 \\
4 & 0.37 & 0.55 \\
5 & 0.29 & 0.40 \\
6 & 0.26 & 0.39 \\
7 & 0.37 & 0.58 \\
8 & 0.55 & 0.65 \\
9 & 0.61 & 0.82 \\
10 & 0.45 & 0.64 \\
11 & 0.56 & 0.52 \\
12 & 0.47 & 0.63 \\
13 & 0.38 & 0.57 \\
14 & 0.35 & 0.47 \\
15 & 0.50 & 0.72 \\
16 & 0.57 & 0.76 \\
17 & 0.36 & 0.54 \\
18 & 0.40 & 0.61 \\
19 & 0.52 & 0.73 \\
20 & 0.56 & 0.77 \\
21 & 0.37 & 0.54 \\
22 & 0.22 & 0.28 \\
23 & 0.74 & 0.91 \\
24 & 0.24 & 0.30 \\
25 & 0.52 & 0.67 \\
26 & 0.34 & 0.45 \\
27 & 0.27 & 0.40 \\
28 & 0.54 & 0.76 \\
29 & 0.57 & 0.75 \\
30 & 0.42 & 0.53 \\
\hline & & \\
& &
\end{tabular}

annual values, excluding the correlation introduced by the standard seasonal variation of the groundwater dynamics, with high values in winter and low values at the end of the summer. This illustrates that the correlations over large distances have a clear physical basis, probably related with anomalies in precipitation and evapotranspiration over large spatial distances.

\subsection{Trends}

The Mann-Kendall trend test is performed for three time periods: 1976-2006, 1961-2006 and 1938-2006. During the short time period of $30 \mathrm{yr}$ all time series could be analyzed and most of them do not show any significant trends (Fig. 6). Seven time series $(5,6,17,21,22,24$ and 26) show significant negative trends. The negative trends are mostly found for spring data, associated with decreasing values since the 1990s (see Fig. 3). Contrary to that, two time series (19 and 27) show positive trends. There is no general spatial pattern and for example the springs around Zurich (17-22), located close to each other show different trends. For the time period of $45 \mathrm{yr}$ in total 22 time series could be analyzed. Results are very similar to the results for the shorter period of $30 \mathrm{yr}$. For the long time period of $68 \mathrm{yr}$ only 12 time series remain to be analyzed. While the springs around Zurich still show the same trends as in the previous time periods, several groundwater level time series $(3,5,12$ and 13) show significant negative trends which cannot be observed in the short time period. The significant negative trends are related to a strong negative trend until the 1970s (Fig. 2). Trend tests were also performed for the recharge calculated with MIKESHE. However, besides one weak positive trend at site 5 no trend in any period can be found.

\subsection{Sensitivity analysis}

The results of the parsimonious model approach may be strongly dependent on the assumptions concerning runoff, soil type and landuse. Neglecting surface runoff could lead to an overestimation of recharge. The choice of soil type and landuse may strongly affect evapotranspiration. To test 

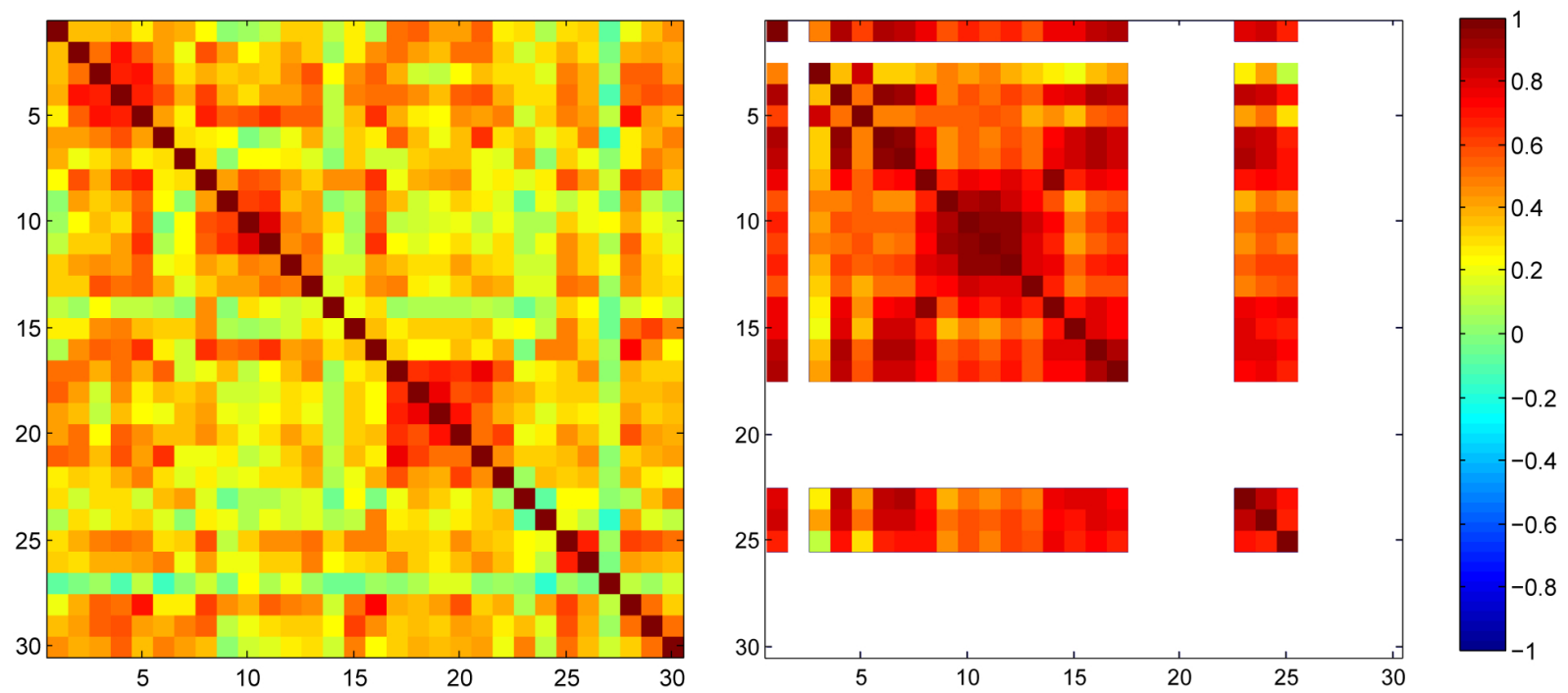

Fig. 5. Spearman correlation coefficients between the different groundwater sites (the numbers correspond to the sites as defined in Table 1 and Fig. 1) for groundwater data (left) and calculated deep percolation (right).

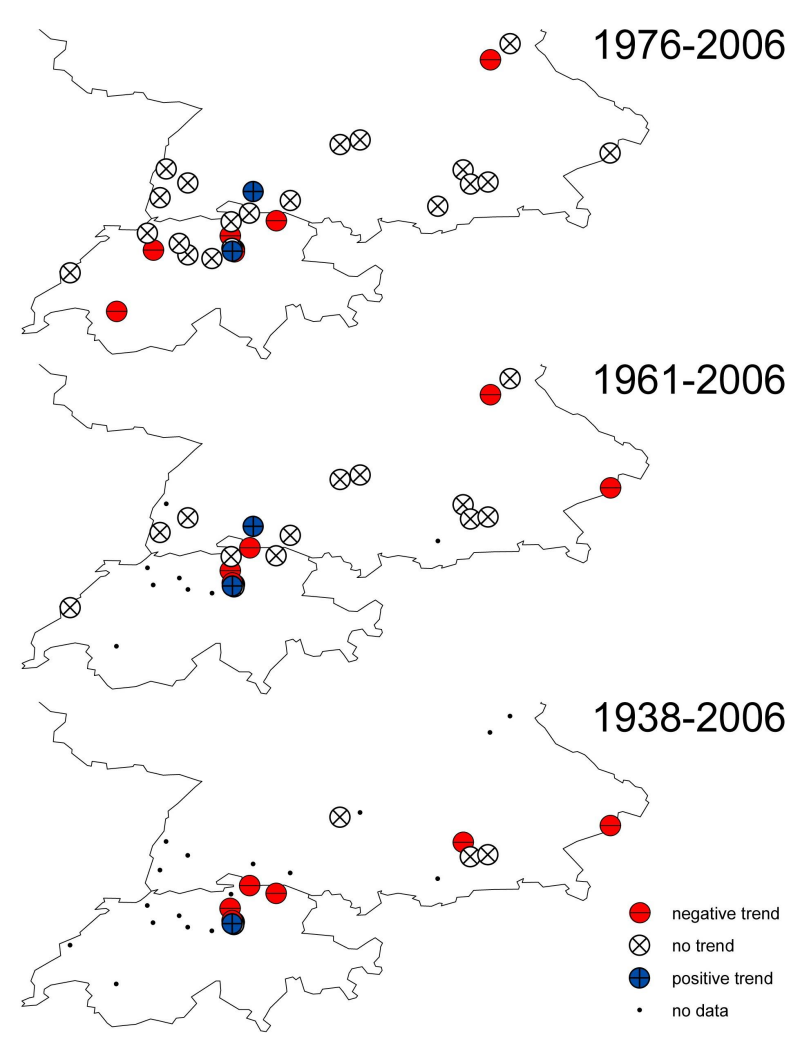

Fig. 6. Observed groundwater trends at the studied sites in northern Switzerland and southern Germany in three different time periods. this, a sensitivity study was performed, where different soil types (from sand to clay) were combined with different land use types and the model was allowed to generate runoff. While we found large differences in absolute recharge sums, hardly any differences in the relative dynamics and trends were visible among the model combinations. For example, for the observation site Niederstotzingen (14) the forest-onsand combination shows the highest recharge sums and no runoff, while the combination meadow-on-clay shows least recharge and most runoff. However, as can be seen from Fig. 7, the differences are hardly visible if the recharge is normalized. The dynamics as well as the trends are almost identical for the different model combinations. Therefore, and in spite of the fact that some rather strong modeling simplifications are made, we expect the modeling approach to be appropriate to analyze the recharge dynamics and trends. The uncertainty related to the assumptions about soil types, land use and runoff seems to be of limited importance.

\section{Discussion}

\subsection{Identification of driving processes}

There are three major processes possibly related to trends and patterns in the time series. First, the groundwater level data (and to a lesser extent also the spring data) can be influenced by changes in the water extraction via pumping. Besides direct pumping, modifications in the amount of water pumped further away from the measurement location could also have influenced the groundwater levels. Second, changes in meteorological forcing might have played a role. Third, also changes in land use have to be considered. Unfortunately 
hardly any specific information about land use changes and water extractions are available for such time scales. Therefore, to distinguish between the three possible processes, a qualitative procedure is developed, based on the different sources of information: groundwater levels, spring outflows and recharge calculations (Fig. 8).

It is assumed, that all three sources of information are subject to the climatic variations. Therefore, if a pattern can be observed in all three, it is likely that this pattern is introduced by the climate. As explained before (see model section), for the model calculations it is assumed that land use was constant over the simulation period. On the other hand, ground water levels and spring discharges can be affected by land use changes. Consequently, if certain patterns of changes are observable in the groundwater level and spring data, but not in the recharge calculations, the observed patterns are likely to be related to land use changes. Additionally we assume that the spring discharges are not, or only weakly influenced by pumping activity, as the springs naturally drain small aquifers from hills without pumping activities. Recharge calculations are also not affected by pumping activity. Accordingly, if certain patterns of changes are observable only in the groundwater data, but not in the spring data and recharge calculations, we assume the patterns to be explained by water extractions.

\subsection{Model calculations}

Apart from the generally good correspondence of the dynamics of groundwater levels, spring discharges and recharge calculations, deviations especially in the trends and timing can be recognized. We assume that deviations are primarily linked to the uncertainty of the climatic input and the uncertainty related to the parsimonious model approach. Especially the processes of the unsaturated zone are of great importance. Although the depth to the groundwater at the observation site is known for the groundwater level sites, this depth is not representative for the whole aquifer. Thus, deviations in the timing are introduced. If the correlation analysis accounts for the time shifts, significant higher correlation coefficients can be reached. In addition, the lack of information about soil properties (e.g. porosity, field capacity) and the influence of the storage behavior of the aquifer can contribute to the deviations between modeled recharge and observed data. Moreover, it has to be taken into account that the observed data (especially the groundwater levels) are subject to anthropogenic actions (like pumping), which are not considered in the recharge calculations. As the spring discharges are assumed to be less affected by pumping, this may be the reason why models perform better for the springs than for the groundwater levels. The deviations related to different trends in the time series will be discussed in Sect. 4.4.

Some groundwater levels show much more pronounced drought periods than model calculations or spring discharges do. According to our classification scheme as explained in Sect. 4.1 this feature would be associated with pumping activity. This feature could be explained by an increased water demand and thus increased pumping. Due to precipitation deficits and increased temperatures during dry periods soil water is depleted and consequently the irrigation demand of agriculture is increased. As groundwater is one of the major water resources used to meet the irrigation demand, this can lead to increased pumping activity and thus significant groundwater drawdowns (e.g. Zhou et al., 2010). Moreover, usually the communal water demand is increased too (e.g. lawn sprinkling). In addition to the naturally low groundwater levels during dry periods further groundwater depletion is introduced by this feedback mechanism.

\subsection{Spatio-temporal correlations}

Strong spatio-temporal correlations are found among observed groundwater data. This is also expressed by the large fractions of explained variances of the first principle components and the results of the uncalibrated models, showing the large correlations too. These results point to the existance of a strong link between homogeneous large-scale meteorological conditions and the recharge of unconfined, precipitation dominated aquifers in the study area. While orographic precipitation might be important for some of the more alpine observations sites and convective events dominate during summer, stratiform precipitation governs the recharge-intensive winter period in the study area. Therefore, for follow-up studies, it would be interesting to analyse the relationship between groundwater droughts and the occurence of atmospheric circulation patterns. Such studies have already been performed for surface water systems (e.g. Fleig et al., 2011; Stahl and Demuth, 1999) and an aquifer in the UK (Holman et al., 2009).

The fact, that the recharge calculations show higher spatial correlations than the observed time series can be explained as follows: (1) for the model calculations, the percolation from the root zone is used, and therefore the time shift with respect to the meteorological signal is relatively limited, as the extension of the root zone is limited. On the other hand, groundwater levels might react with a large delay with respect to a meteorological signal as the unsaturated zone for some of the sites is rather thick. (2) The model is an idealistic, parsimonious representation of the reality and thus cannot account for all the differences (e.g. soil properties, land use and water demand changes) among the aquifer catchments.

Although significant correlations are found over large distances, unsurprisingly, spatial proximity is the major reason for high correlations. The patches of high correlations are usually found for time series which are located close to each other. The very low correlations found for the observation site 27 may be linked to different dynamics of the karstic underground. However, other karstic groundwater data do not show such a response. To resolve this question additional specific information about this particular spring 


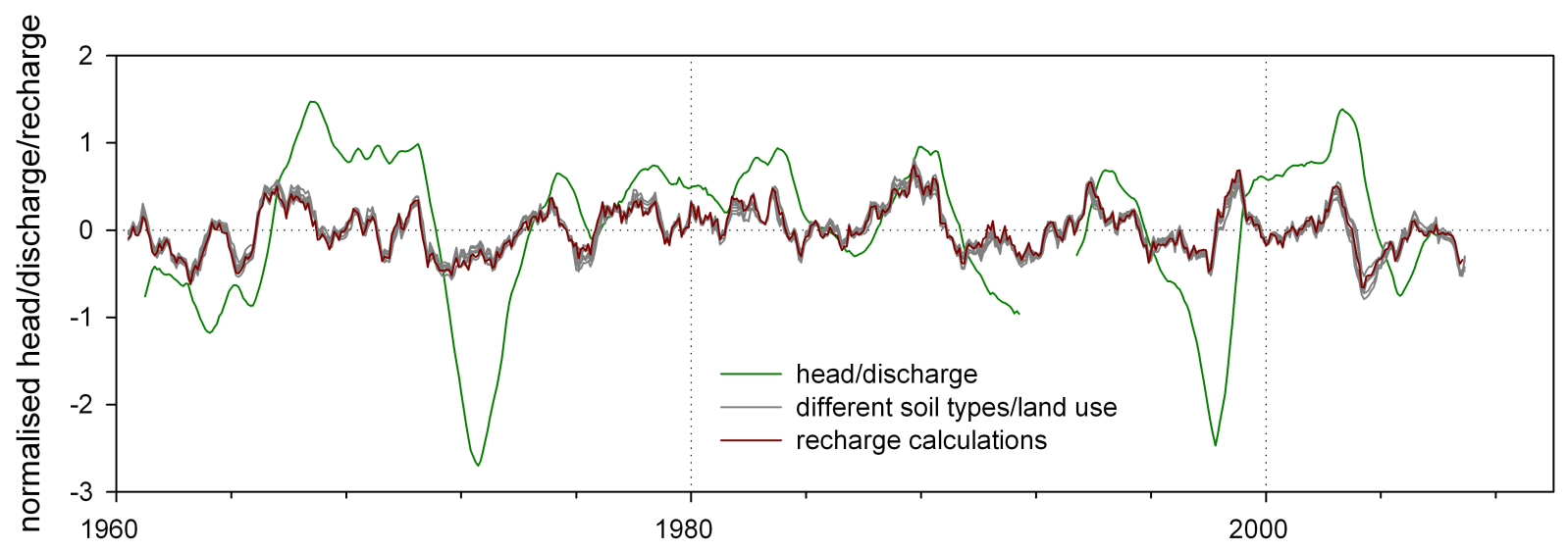

Fig. 7. Normalized monthly recharge sums for eight different model combinations (grey), the result from the original model setup (red) and the observed normalized groundwater level (green) at the observation site Niederstotzingen (14).

\section{assumptions pattern observable? caused by}

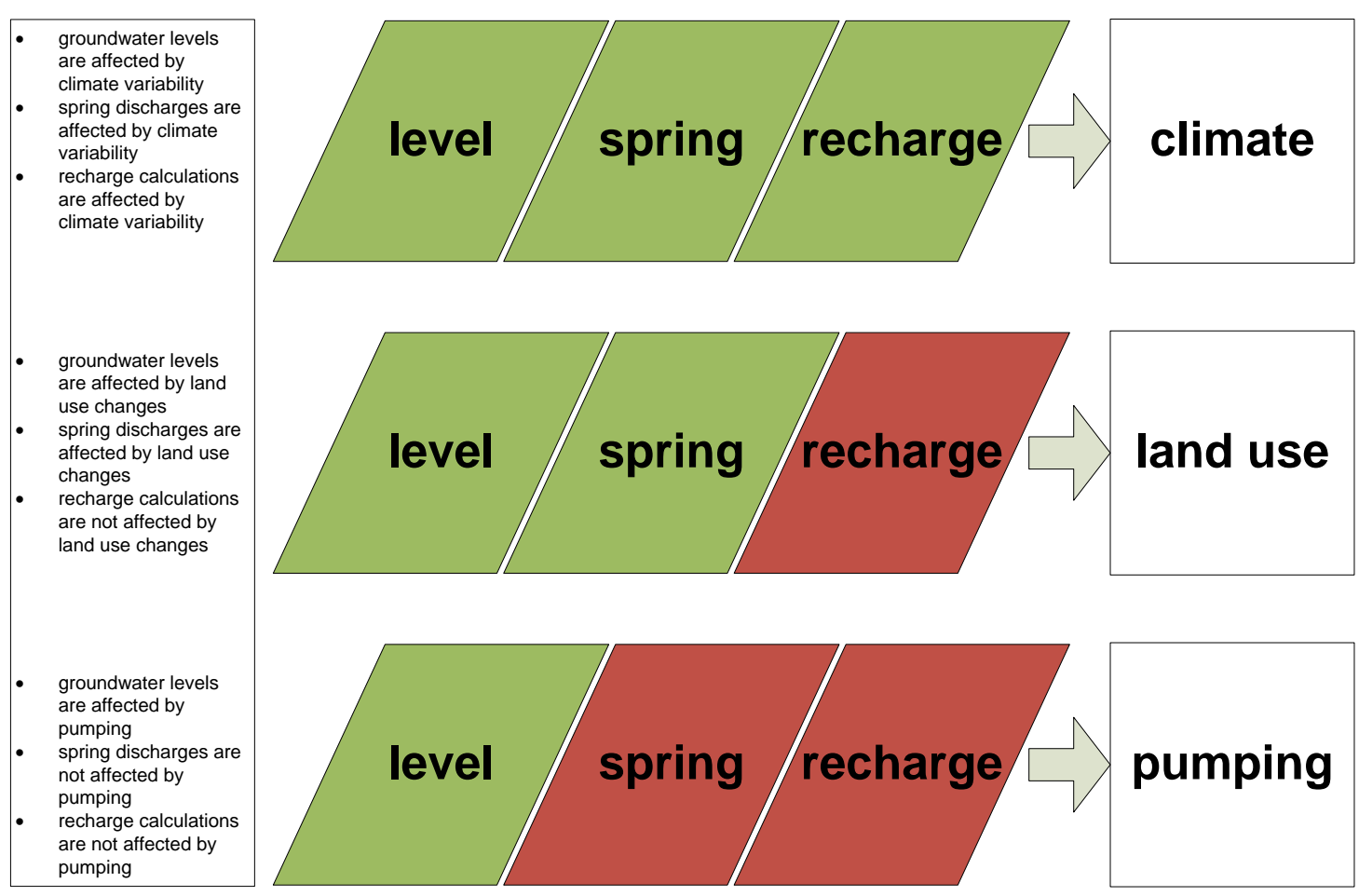

Fig. 8. Qualitative procedure to identify the possible reasons for observed patterns. If a pattern (e.g. a trend) can be observed in a specific data source (e.g. groundwater level) it is marked green. If not, the data source is marked red. Other combinations than the ones displayed, did not occur.

would be needed. Generally, geological properties, land use and elevation seem to be of only minor importance for the groundwater dynamics. Besides the correlation coefficients, also the PCA loadings do not hint to a specific clustering according to these site characteristics.

The groundwater and recharge dynamics as characterized by the PCA scores are mainly controlled by the amount and the temporal distribution of the precipitation. Especially winter precipitation seems to be crucial as according to the model results $2 / 3$ of the annual recharge is generated during the winter half year (October-March). Precipitation during winter is more effective in recharging the groundwater, as less water is lost to evapotranspiration. Therefore also droughts tend to be more severe if the precipitation deficits fall into the winter 

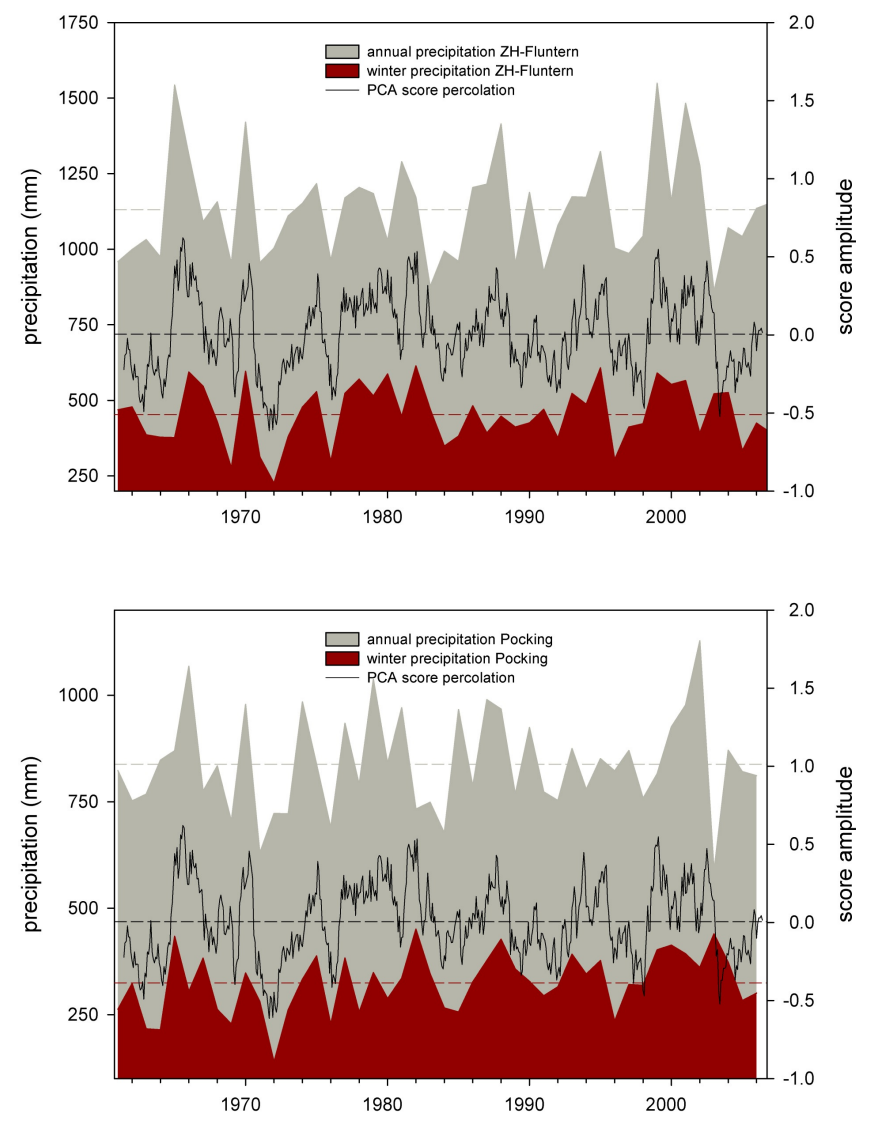

Fig. 9. Precipitation at the station Zurich-Fluntern (top) and Pocking (bottom) and the PCA score of the root zone percolation during the period 1961-2006. Dashed lines represent the yearly mean values of annual precipitation, percolation and winter precipitation during the period.

half year. For example the major drought 1971-1973 is associated with exceptionally dry winters. At the station ZurichFluntern, the winters of 1970/1971 and 1971/1972 belong to the top five of the driest winters in the period 1961-2006 (Fig. 9). With only $139 \mathrm{~mm}$, the winter $1971 / 1972$ is by far the driest one at the station Pocking, in the eastern part of the study area. Besides the temporal distribution, the total annual precipitation amount (e.g. 2003) and in particular the succession of dry years (e.g. 1962-1964) is linked to groundwater droughts. These major drought events have a large spatial extension and can be recognized in the whole study area. Generally drought periods according to the PCA agree well with a recent study analyzing stream discharges and climatic drought indicators (Hannaford et al., 2011).

\subsection{Trend analysis}

While the trend tests for the model calculations, which are forced by measured climatic data, do not show significant trends, some trends (mostly negative) can be detected for the observed time series. However, these trends are not homogeneous and can have different signs for sites located very close to each other (less than two kilometers). Thus it is likely that climatic reasons can be excluded. Based on the identification scheme, the trends are then assumed to be connected to land use change or pumping activity. The trends detected during the short time period 1961-2006 are mainly driven by decreasing values since 1985 and are primarily found at spring locations. A differentiation between land use change and pumping introduced trends is difficult because no specific information is available for any observation site. However, as already stated in Sect. 4.1 we assume that aquifers drained by springs are usually less affected by pumping and that therefore the trends are caused by land use change. For the observation sites 17, 21 and 22 this can be verified by the cantonal groundwater map (SGK, 1986) which does not designate any pumping wells in the corresponding aquifers. As most spring sites are located in rural and remote areas, afforestation respectively deforestation seems to be a more likely explanation for the trends than changes in surface sealing. Additionally, also the response of the foliar phenology to increased temperatures and thus increasing transpiration might play a role. However, the question arises why this would be only visible for some monitoring sites while others show a different behavior.

Contrary to the short time period, the trends identified in the long period 1938-2006 are likely to be associated with changes in pumping activity and land use change seems to be only of minor importance. While the trends of the spring flow time series are mainly dominated by the dynamics at the end of the century, the negative trends observed for the groundwater levels originate in decreasing values until the 1970s. These trends correspond well with the development of groundwater extraction as reported by the Swiss Association of Water and Gas Suppliers (SVGW, 2010). The increasing water extractions which reach their peak in the 1970s are driven by population growth and stay more or less constant until the 1990s. After that even a slight decrease is visible which is usually associated with the increased environmental awareness of the consumers.

\section{Conclusions}

30 groundwater time series in northern Switzerland and southern Germany were analyzed to deliver insights about processes dominating the groundwater dynamics and thus potential future risks. Although, information about anthropogenic actions was not available, it was possible to identify processes which dominated the groundwater dynamics in the past. It could be shown that besides the meteorological conditions and land use changes also pumping activity and feedback mechanisms are very important. In the following the implications of the results on climate change impact studies are summarized. We think that there are lessons worthwhile to consider in future impact studies: 
1. The principle component analysis (PCA) of observed groundwater data and recharge calculations revealed a strong signal of past meteorological conditions in the groundwater dynamics and similar to previous studies (Warren, 1994; Bradford, 2000) a strong relationship between winter precipitation and groundwater droughts. The results emphasize the importance of a detailed representation of the temporal precipitation distribution in impact studies. If the future temporal distribution is not described correctly, this would result in wrong projections of future recharge. Consequently, the application of uniform annual change factors seems not to be sufficient to describe changes in future precipitation, as also the intra-annual distribution is likely to change. This is also of importance when choosing a downscaling method. Methods not accounting for intra-annual biases are not recommended.

2. The detected strong spatial correlations among observation sites (both in data and model calculations) point to the existence of a distinct relationship between largescale atmospheric circulation patterns and groundwater dynamics. This information can also be of help when deciding for a downscaling method. A major problem of impact studies is the high uncertainty related to the precipitation output of the climate models. It is known (e.g. Hewitson and Crane, 1996) that the uncertainty regarding pressure (and thus atmospheric circulation) is considerably smaller. There is a strong relationship between atmospheric circulation patterns and climate variables such as precipitation (Bárdossy and Plate, 1992), which can be used for downscaling approaches. Given this and the result that there is a clear large-scale meteorological signal in the groundwater dynamics, we recommend preferring innovative weather-type-based downscaling methods (e.g. Willems and Vrac, 2011; Bárdossy and Pegram, 2011) to other stochastic downscaling approaches.

3. The trend analysis revealed that in the past, the water demand dominated the evolution of some groundwater levels. The negative trends introduced by the pumping exhibit the variations of the climatic conditions significantly. Scenarios for changes in the water demand are not included in impact studies as a standard feature. More often only land use changes are considered. However, it is likely, that the water demand will also change in future. For example in southern Germany detailed integrated simulations of changing water demands and landuse and the respective feedbacks on groundwater levels have been presented by Barthel et al. (2008), Barthel et al. (2010) and Soboll et al. (2011). For Switzerland, Fuhrer and Jasper (2009) have shown that increasing temperatures will likely lead to increasing irrigation demand and thus increasing pressure on groundwater resources.
Besides the socio-economic changes driven by climate change also socio-economic changes which are not related to climate should be considered. For example, due to increased immigration to Switzerland, a population growth of 1 million is expected until the year 2035 (BFS, 2010), which will not only lead to a higher demand but in turn can also lead to significant changes in land use. On the other hand, water efficient technologies and increased environmental awareness might mitigate the increased water demand. Nonetheless it is generally recommended that both water demand (for agriculture, industry and households) and land use scenarios for aquifers are included in climate change impact studies. Past measurement data anyway contain the impact of all of those.

4. Related to the previous point, an increased water demand due to increased temperatures and precipitation deficits can trigger groundwater droughts in dry periods. As seen for example in 2003 in Switzerland, the supply with groundwater is most vulnerable during dry summers (BUWAL, 2004). A peak in the demand coincides with low availability due to empty storages. The importance of the feedback mechanism could increase in a future climate. For example for Switzerland, a recent study (CH2011, 2011) showed, that climate models expect increasing temperatures and drier summers. Therefore, when analyzing the vulnerability of used groundwater systems under climate change, it is important to consider the observed feedback mechanism. A possible implementation strategy would be to relate the water demand to climatic drought indices. Also it is essential to focus on the extreme groundwater drought periods rather than analyzing annual averages.

It is important to mention that these recommendations and analyses are primarily valid for studies in unconfined and precipitation dominated groundwater systems. In aquifers dominated by river-groundwater interactions, other processes such as changes in snow distribution in the corresponding catchment might be equally or even more important.

Acknowledgements. This study was performed in the context of the working group "Climate and Groundwater" of the Swiss Hydrogeological Society. We thank David Bendel for his support and we are indebted to the working group "Climate and Groundwater" of the Swiss Hydrogeological Society, the Baden-Württemberg State Environmental Agency, the Bavaria State Environmental Agency and Wolfram Mauser (LMU Munich) for providing the data used in this study. The study was supported by SNF Project No. 200021_121862.

Edited by: N. Basu 


\section{References}

Allen, G. A., Pereira, L. S., Raes, D., and Smith, M.: Crop Evapotranspiration - guidelines for Computing Crop Water Requirements, FAO Irrig. Drain., 56, 78-86, 1998.

Barco, J., Hogue, T. S., Girotto, M., Kendall, D. R., and Putti, M.: Climate signal propagation in southern California aquifers, Water Resour. Res., 46, W00f0510, doi:1029/2009wr008376, 2010.

Bárdossy, A. and Pegram, G.: Downscaling precipitation using regional climate models and circulation patterns toward hydrology, Water Resour. Res., 47, W04505, doi:10.1029/2010wr009689, 2011.

Bárdossy, A. and Plate, E. J.: Space-time model for daily rainfall using atmospheric circulation patterns, Water Resour. Res., 28, 1247-1259, doi:10.1029/91wr02589, 1992.

Barthel, R., Janisch, S., Schwarz, N., Trifkovic, A., Nickel, D., Schulz, C., and Mauser, W.: An integrated modelling framework for simulating regional-scale actor responses to global change in the water domain, Environ. Modell. Softw., 23, 1095-1121, 2008.

Barthel, R., Janisch, S., Nickel, D., Trifkovic, A., and Hörhan, T.: Using the Multiactor-Approach in GLOWA-Danube to Simulate Decisions for the Water Supply Sector Under Conditions of Global Climate Change, Water Resour. Manag., 24, 239-275, doi:10.1007/s11269-009-9445-y, 2010.

Bastola, S., Murphy, C., and Sweeney, J.: The role of hydrological modelling uncertainties in climate change impact assessments of Irish river catchments, Adv. Water Resour., 34, 562-576, 2011.

Beven, K.: I believe in climate change but how precautionary do we need to be in planning for the future?, Hydrol. Process., 25, 1517-1520, doi:10.1002/hyp.7939, 2011.

BFS: Szenarien zur Bevölkerungsentwicklung der Schweiz 20102060, Schriftenreihe Statistik der Schweiz, Bundesamt fr Statistik, Neuchâtel, 2010.

Blöschl, G. and Montanari, A.: Climate change impacts-throwing the dice?, Hydrol. Process., 24, 374-381, doi:10.1002/hyp.7574, 2010.

Bradford, R. B.: Drought events in Europe, in: Drought and Drought Mitigation in Europe, edited by: Vogt, J. V. and Somma, F., Kluwer Academic Publishers, 2000.

BUWAL: Auswirkungen des Hitzesommers 2003 auf die Gewässer, Schriftenreihe Umwelt Nr. 369, Bundesamt für Umwelt, Wald und Landschaft, Bern, 2004.

CH2011: Swiss Climate Change Scenarios CH2011, published by C2SM, MeteoSwss, ETH, NCCR Climate, and OcCC, Zurich, Switzerland, 88 pp., 2011.

Chen, J., Brissette, F. P., and Leconte, R.: Uncertainty of downscaling method in quantifying the impact of climate change on hydrology, J. Hydrol., 401, 190-202, 2011.

Chen, Z., Grasby, S. E., and Osadetz, K. G.: Relation between climate variability and groundwater levels in the upper carbonate aquifer, southern Manitoba, Canada, J. Hydrol., 290, 43-62, 2004.

Crosbie, R. S., Dawes, W. R., Charles, S. P., Mpelasoka, F. S., Aryal, S., Barron, O., and Summerell, G. K.: Differences in future recharge estimates due to GCMs, downscaling methods and hydrological models, Geophys. Res. Lett., 38, L11406, doi:10.1029/2011g1047657, 2011.

Fiorillo, F. and Guadagno, F.: Karst Spring Discharges Analysis in Relation to Drought Periods, Using the SPI, Water Resour.
Manag., 24, 1867-1884, doi:10.1007/s11269-009-9528-9, 2010.

Fleig, A. K., Tallaksen, L. M., Hisdal, H., and Hannah, D. M.: Regional hydrological drought in north-western Europe: linking a new Regional Drought Area Index with weather types, Hydrol. Process., 25, 1163-1179, doi:10.1002/hyp.7644, 2011.

Fowler, H. J., Blenkinsop, S., and Tebaldi, C.: Linking climate change modelling to impacts studies: recent advances in downscaling techniques for hydrological modelling, Int. J. Climatol., 27, 1547-1578, doi:10.1002/joc.1556, 2007.

Fuhrer, J. and Jasper, K.: Bewässerungsbedürftigkeit von Ackerund Grasland im heutigen Klima, Agrarforschung, 16, 396-401, 2009.

Gosling, S. N., Taylor, R. G., Arnell, N. W., and Todd, M. C.: A comparative analysis of projected impacts of climate change on river runoff from global and catchment-scale hydrological models, Hydrol. Earth Syst. Sci., 15, 279-294, doi:10.5194/hess-15279-2011, 2011.

Graham, D. N. and Butts, M. B.: Flexible integrated watershed modeling with MIKE SHE, in: Watershed models, edited by: Singh, V. P. and Frevert, D. K., CRC Press, 245-272, 2006.

Green, T. R., Taniguchi, M., Kooi, H., Gurdak, J. J., Allen, D. M., Hiscock, K. M., Treidel, H., and Aureli, A.: Beneath the surface of global change: Impacts of climate change on groundwater, J. Hydrol., 405, 532-560, 2011.

Hannaford, J., Lloyd-Hughes, B., Keef, C., Parry, S., and Prudhomme, C.: Examining the large-scale spatial coherence of European drought using regional indicators of precipitation and streamflow deficit, Hydrol. Process., 25, 1146-1162, doi:10.1002/hyp.7725, 2011.

Hanson, R., Dettinger, M., and Newhouse, M.: Relations between climatic variability and hydrologic time series from four alluvial basins across the southwestern United States, Hydrogeol. J., 14, 1122-1146, doi:10.1007/s10040-006-0067-7, 2006.

Helena, B., Pardo, R., Vega, M., Barrado, E., Fernandez, J. M., and Fernandez, L.: Temporal evolution of groundwater composition in an alluvial aquifer (Pisuerga River, Spain) by principal component analysis, Water Res., 34, 807-816, 2000.

Hewitson, B. C. and Crane, R. G.: Climate downscaling: techniques and application, Clim. Res., 07, 85-95, 1996.

Holman, I. P., Rivas-Casado, M., Howden, N. J. K., Bloomfield, J. P., and Williams, A. T.: Linking North Atlantic ocean-atmosphere teleconnection patterns and hydrogeological responses in temperate groundwater systems, Hydrol. Process., 23, 3123-3126, doi:10.1002/hyp.7466, 2009.

Kendall, M. G.: Rank Correlation Methods, Charles Griffin, London, 1975.

Kingston, D. G. and Taylor, R. G.: Sources of uncertainty in climate change impacts on river discharge and groundwater in a headwater catchment of the Upper Nile Basin, Uganda, Hydrol. Earth Syst. Sci., 14, 1297-1308, doi:10.5194/hess-14-12972010, 2010.

Kristensen, K. J. and Jensen, S. E.: A model for estimating actual evapotranspiration from potential transpiration, Nord. Hydrol., 6 , 79-88, 1975.

Mann, H. B.: Non-parametric test against trend, Econometrica, 13, 245-259, 1945.

Mauser, W. and Bach, H.: PROMET -Large scale distributed hydrological modelling to study the impact of climate change on the water flows of mountain watersheds, J. Hydrol., 376, 362- 
377, 2009.

Mualem, Y.: A new model for predicting the hydraulic conductivity of unsaturated porous media, Water Resour. Res., 12, 513-522, 1976.

Okkonen, J. and Klove, B.: A conceptual and statistical approach for the analysis of climate impact on ground water table fluctuation patterns in cold conditions, J. Hydrol., 388, 1-12, doi:10.1016/j.jhydrol.2010.02.015, 2010.

Rivard, C., Vigneault, H., Piggott, A. R., Larocque, M., and Anctil, F.: Groundwater recharge trends in Canada, Can. J. Earth Sci., 46, 841-854, doi:10.1139/E09-056, 2009.

Ryu, J., Svoboda, M., Lenters, J., Tadesse, T., and Knutson, C.: Potential extents for ENSO-driven hydrologic drought forecasts in the United States, Climatic Change, 101, 575-597, doi:10.1007/s10584-009-9705-0, 2010.

Sen, P. K.: Estimates of the Regression Coefficient Based on Kendall's Tau, J. Am. Stat. Assoc., 63, 1379-1389, 1968.

SGK: Die Grundwasservorkommen in Kanton Zürich, Erläuterungen zur Grundwasserkarte 1:25000, Schweizerische Geotechnischen Kommission, Lieferung 69, Kümmerly \& Frei Verlag, Bern, 1986.

Soboll, A., Elbers, M., Barthel, R., Schmude, J., Ernst, A., and Ziller, R.: Integrated regional modelling and scenario development to evaluate future water demand under global change conditions, Mitigation and Adaptation Strategies for Global Change, 16, 477-498, doi:10.1007/s11027-010-9274-6, 2011.

Stahl, K. and Demuth, S.: Linking streamflow drought to the occurrence of atmospheric circulation patterns, Hydrolog. Sci. J., 44, 467-482, 1999.

Stoll, S., Hendricks Franssen, H. J., Butts, M., and Kinzelbach, W.: Analysis of the impact of climate change on groundwater related hydrological fluxes: a multi-model approach including different downscaling methods, Hydrol. Earth Syst. Sci., 15, 21-38, doi:10.5194/hess-15-21-2011, 2011.
SVGW: Schweizerischer Verein des Gas- und Wasserfaches, Wasserstatistik 2010, Betriebsjahr 2009, 2010.

van Genuchten, M. T.: A closed-form equation for predicting the hydraulic conductivity of unsaturated soils, Soil Sci. Soc. Am., 44, 892-898, 1980.

von Storch, V. H.: Misuses of statistical analysis in climate research, in: Analysis of Climate Variability: Applications of Statistical Techniques, edited by: von Storch, V. H. and Navarra, A., Springer, Berlin, 1995.

Wada, Y., van Beek, L. P. H., van Kempen, C. M., Reckman, J. W. T. M., Vasak, S., and Bierkens, M. F. P.: Global depletion of groundwater resources, Geophys. Res. Lett., 37, L20402, doi:10.1029/2010g1044571, 2010.

Warren, G. D.: Drought in the south - implications for the management of groundwater resources, in: Groundwater - Drought, Pollution and Management, edited by: Reeve, C. and Watts, H., Balkema, Rotterdam (NL), 1994.

Willems, P. and Vrac, M.: Statistical precipitation downscaling for small-scale hydrological impact investigations of climate change, J. Hydrol., 402, 193-205, 2011.

Yue, S. and Wang, C. Y.: Applicability of prewhitening to eliminate the influence of serial correlation on the Mann-Kendall test, Water Resour. Res., 38, 1068-1075, doi:10.1029/2001wr000861, 2002.

Zhang, J., van Heyden, J., Bendel, D., und R. Barthel: Combination of soil-water balance models and water table fluctuation methods for improvement and validation of groundwater recharge calculations, Hydrogeology Journal, 19, 1487-1502, 2011.

Zhou, Y., Zwahlen, F., Wang, Y., and Li, Y.: Impact of climate change on irrigation requirements in terms of groundwater resources, Hydrogeol. J., 18, 1571-1582, doi:10.1007/s10040010-0627-8, 2010. 